\title{
Performance evaluation of portable air quality measurement system using raspberry $P i$ for remote monitoring
}

\author{
Muhammad Farhan Mohd Pu'ad', Teddy Surya Gunawan², Mira Kartiwi ${ }^{3}$, Zuriati Janin ${ }^{4}$ \\ ${ }^{1,2}$ Department of Electrical and Computer Enginering, International Islamic University Malaysia, Malaysia \\ ${ }^{2}$ School of Electrical Engineering and Telecommunications, University of New South Wales, Australia \\ ${ }^{3}$ Departement of Information Systems, International Islamic University Malaysia, Malaysia \\ ${ }^{4}$ Faculty of Electrical Engineering, Universiti Teknologi MARA, Malaysia
}

\begin{tabular}{l}
\hline \hline Article Info \\
\hline Article history: \\
Received Jun 5, 2019 \\
Revised Aug 6, 2019 \\
Accepted Aug 20, 2019
\end{tabular}

\section{Keywords:}

Air pollution

Air pollution index

Air quality measurement

Gas sensors

Internet of things

PM2.5

Raspberry Pi

Remote monitoring

\begin{abstract}
United Nations' Sustainable Development Goals focuses on good health and well-being for all. Air pollution becomes a huge threat to delivering on the vision of a better world and related at least to Goal 3, 7, 11, and 13. In Malaysia, air pollution index were monitored on 68 locations. The Department of Environment monitors air quality using costly continuous air quality monitoring stations (CAQMs) installed at fixed locations of highly populated and industrial areas. The objective of this paper is to develop a portable air quality measurement system which can measure particulate matters (PM) smaller than 10 and 2.5 microns, and four hazardous gasses, including carbon monoxide, sulphur dioxide, ground level ozone and nitrogen dioxide, as well as humidity and temperature. Six sensors were used and validated using several rigorous experiments. The functionality of the system was evaluated by measuring sub-API readings in areas with low and high traffic volumes. Experimental results showed that the proposed system was highly responsive and able to detect the types and concentrations of air pollutants instantly. Furthermore, equipped with the mobile internet, geo-tagged GPS location and web server on Raspberry Pi, the developed portable system could be accessed remotely.
\end{abstract}

Copyright @ 2020 Institute of Advanced Engineering and Science. All rights reserved.

\section{Corresponding Author:}

Teddy Surya Gunawan,

Department of Electrical and Computer Engineering,

Internation Islamic University Malaysia, Malaysia.

Email: tsgunawan@iium.edu.my

\section{INTRODUCTION}

Air pollutant is recognised as the fourth in risk factor for death around the world. For instance, in 2013 alone, around 3 million people in Asia have died due to sickness related to air pollution [1, 2]. In Malaysia as well as China, there are four types of hazardous gasses being categorized as major pollutants based on the new Malaysia Ambient Air Quality Standard namely $\mathrm{CO}, \mathrm{NO}_{2}, \mathrm{SO}_{2}$ and $\mathrm{O}_{3}$ [3]. Air pollution is highly related with the climate change [4] and the increased risk to premature mortality [4, 5]. For particulate matter, the country has recognized two particulate matters which could endanger health, e.g. cardiovascular [6] as well as metabolic disease and cancer [7], namely those with the size of less than 10 microns $\left(\mathrm{PM}_{10}\right)$ and 2.5 micron $\left(\mathrm{PM}_{2.5}\right)$ [8, 9]. The United Nations' Sustainable Development Goals (SDG) aim to end extreme povery and create a healthy, sustainable world by the year 2030 [10]. Air pollution becomes a huge threat to delivering on the vision of a better world and related at least to Sustainable Development Goal number $3,7,11$, and 13 [11].

While the detection system is quite efficient in estimating the levels of pollution, the location where the system is stationed could compromise the data for areas where the system is not available. In Malaysia, the Department of Environment places 68 continuous air quality monitoring station (CAQMs) permanently in 
highly populated and industrial areas, as of July 2019. Thus, many areas are beyond the coverage of the system and their API readings are just an estimate based on the reading from the nearest CAQMs which could be inaccurate [12].

Many research have been conducted on the air quality measurement system using Arduino [12]. Wireless sensor network (WSN) has been used along with Raspberry Pi, Arduino, and Zigbee to monitor the environment [13] using low cost sensors [14]. Two gas sensors, temperature, humidity, and atmospheric pressure sensors, were utilized in [15]. Smartphone with additional device was used to form crowd-sensing [16-18]. Limited environmental monitoring using Raspberry Pi has also been proposed in [19-21]. Although many researches have been conducted on limited air pollution monitoring, however further research is still required to improve the accuracy, portability, and features.

In our previous work [22], the design and prototype implementation of air quality measurement system using Raspberry Pi has been discussed. Hardware and software design were elaborated in details. The objective of this paper is to conduct performance evaluation and validation for each sensor as well as to evaluate the performance on different road traffic volumes. Additionally, web server was introduced to enable remote access and monitoring of the air quality.

\section{AIR POLLUTION INDEX (API) CALCULATION}

The main objective of establishing the Air Pollution Index (API) is to inform public on the levels of pollutants in the surrounding air. The Malaysian API is calculated based on the new Malaysia Ambient Air Quality Standard which was introduced in 2014 [23]. Under this new standard, six types of pollutants are being monitored namely $\mathrm{CO}, \mathrm{NO}_{2}, \mathrm{SO}_{2}, \mathrm{O}_{3}$ and particulate matters of 10 microns $\left(\mathrm{PM}_{10}\right)$ and less than 2.5 microns $\left(\mathrm{PM}_{2.5}\right)$.

The main purpose of ambient air quality standard is to determine the levels of these pollutants that are safe for human and the environment [24]. Although the government has already implemented the new Malaysian Ambient Air Quality Standard in 2013, the standard is not fully implemented in full scale but in stage until 2020. Before that year, two interim targets were set namely interim target 1 (IT-1) in 2015 where the levels of pollutants were set to certain levels and interim target 2 (IT-2) where the levels of pollutants were further reduced in 2018 as shown in Table 1. Sub-API calculation for each pollutant is as follows [12]:

SubAPI $_{C O}=\left\{\begin{array}{cc}C_{C O} \times 11.11111, & C_{C O}<9 \mathrm{ppm} \\ 100+\left(C_{C O}-9\right) \times 16.66667, & 9 \mathrm{ppm}<C_{C O}<15 \mathrm{ppm} \\ 200+\left(C_{C O}-15\right) \times 6.6667, & 15 \mathrm{ppm}<C_{C O}<30 \mathrm{ppm} \\ 300+\left(C_{C O}-30\right) \times 10, & C_{C O}>30 \mathrm{ppm}\end{array}\right.$

where $C_{C O}$ is the concentration of $\mathrm{CO}$.

$$
\text { SubAPI }_{O_{3}}=\left\{\begin{array}{cc}
C_{O_{3}} \times 1000, & C_{O_{3}}<0.2 p p m \\
200+\left(C_{O_{3}}-0.2\right) \times 500, & 0.2 p p m<C_{O_{3}}<0.4 p p m \\
300+\left(C_{O_{3}}-0.4\right) \times 1000, & C_{O_{3}}>0.4 p p m
\end{array}\right.
$$

where $C_{O_{3}}$ is the concentration of $\mathrm{O}_{3}$.

$$
\text { SubAPI }_{\mathrm{NO}_{2}}=\left\{\begin{array}{cc}
C_{\mathrm{NO}_{2}} \times 588.24, & C_{\mathrm{NO}_{2}}<0.17 \mathrm{ppm} \\
100+\left(C_{\mathrm{NO}_{2}}-0.17\right) \times 232.56, & 0.17 \mathrm{ppm}<C_{\mathrm{NO}_{2}}<0.6 \mathrm{ppm} \\
200+\left(C_{\mathrm{NO}_{2}}-0.6\right) \times 166.67, & 0.6 \mathrm{ppm}<C_{\mathrm{NO}_{2}}<1.2 \mathrm{ppm} \\
300+\left(C_{\mathrm{NO}_{2}}-1.2\right) \times 250, & C_{\mathrm{NO}_{2}}>1.2 \mathrm{ppm}
\end{array}\right.
$$

where $C_{\mathrm{NO}_{2}}$ is the concentration of $\mathrm{NO}_{2}$.

$$
\mathrm{SubAPI}_{\mathrm{SO}_{2}}=\left\{\begin{array}{cc}
\mathrm{C}_{\mathrm{SO}_{2}} \times 2500, & \mathrm{C}_{\mathrm{SO}_{2}}<0.04 \mathrm{ppm} \\
100+\left(C_{\mathrm{SO}_{2}}-0.04\right) \times 384.61, & 0.04 \mathrm{ppm}<C_{\mathrm{SO}_{2}}<0.3 \mathrm{ppm} \\
200+\left(C_{\mathrm{SO}_{2}}-0.04\right) \times 333.33, & 0.3 \mathrm{ppm}<C_{\mathrm{SO}_{2}}<0.6 \mathrm{ppm} \\
300+\left(C_{\mathrm{SO}_{2}}-0.6\right) \times 500, & C_{\mathrm{SO}_{2}}>0.6 \mathrm{ppm}
\end{array}\right.
$$

where $C_{\mathrm{SO}_{2}}$ is the concentration of $\mathrm{SO}_{2}$. 


$$
\text { SubAPI }_{P M}=\left\{\begin{array}{cc}
C_{P M}, & C_{P M}<50 \mu \mathrm{g} / \mathrm{m}^{3} \\
50+\left(C_{P M}-50\right) \times 0.5, & 50 \mu \mathrm{g} / \mathrm{m}^{3}<C_{P M}<150 \mu \mathrm{g} / \mathrm{m}^{3} \\
100+\left(C_{P M}-150\right) \times 0.5, & 150 \mu \mathrm{g} / \mathrm{m}^{3}<C_{P M}<350 \mu \mathrm{g} / \mathrm{m}^{3} \\
200+\left(C_{P M}-350\right) \times 1.43, & 350 \mu \mathrm{g} / \mathrm{m}^{3}<C_{P M}<420 \mu \mathrm{g} / \mathrm{m}^{3} \\
300+\left(C_{P M}-420\right) \times 1.25, & 420 \mu \mathrm{g} / \mathrm{m}^{3}<C_{P M}<500 \mu \mathrm{g} / \mathrm{m}^{3} \\
400+\left(C_{P M}-500\right), & C_{P M}>500 \mu \mathrm{g} / \mathrm{m}^{3}
\end{array}\right.
$$

where $C_{P M}$ is the concentration of PM. The final API value can be determined as follows:

$$
A P I=\operatorname{Max}\left(\operatorname{SubAPI}_{C O}, \quad \operatorname{SubAPI}_{\mathrm{O}_{3}}, \quad \mathrm{SubAPI}_{\mathrm{NO}_{2}}, \quad \mathrm{SubAPI}_{\mathrm{SO}_{2}}, \quad \mathrm{SubAPI}_{P M}\right)
$$

In Malaysia, air quality is measured by the Department of Environment (DOE) using Continuous Air Quality Monitoring station (CAQMs). CAQMs is an integrated system designed to observe ambient air for pollutants. The system is placed in all states and federal territories of Malaysia. Currently, there are 68 air quality monitoring stations been built around the country as shown in Figure 1.

Table 1. New Ambient Air Quality Standard

\begin{tabular}{lcccc}
\hline \multirow{2}{*}{ Pollutants } & Averaging Time & $\begin{array}{c}I T-1(2015) \\
\mu \mathrm{g} / \mathrm{m}^{3}\end{array}$ & $\begin{array}{c}\text { Ambient Air Quality } \\
I T-2(2018) \\
\mu \mathrm{g} / \mathrm{m}^{3}\end{array}$ & $\begin{array}{c}\text { Standard }(2020) \\
\mu \mathrm{g} / \mathrm{m}^{3}\end{array}$ \\
\hline \multirow{2}{*}{ Carbon monoxide $(\mathrm{CO})$} & 1 hour & $35\left(\mathrm{mg} / \mathrm{m}^{3}\right)$ & $35\left(\mathrm{mg} / \mathrm{m}^{3}\right)$ & $30\left(\mathrm{mg} / \mathrm{m}^{3}\right)$ \\
& 8 hours & $10\left(\mathrm{mg} / \mathrm{m}^{3}\right)$ & $10\left(\mathrm{mg} / \mathrm{m}^{3}\right)$ & $10\left(\mathrm{mg} / \mathrm{m}^{3}\right)$ \\
Ozone $\left(\mathrm{O}_{3}\right)$ & 1 hour & 200 & 200 & 180 \\
& 8 hours & 120 & 120 & 100 \\
Nitrogen dioxide $\left(\mathrm{NO}_{2}\right)$ & 1 hour & 320 & 300 & 280 \\
Sulfur dioxide $\left(\mathrm{SO}_{2}\right)$ & 8 hours & 75 & 75 & 250 \\
& 1 hour & 350 & 200 & 80 \\
$\mathrm{PM}_{10}$ & 24 hours & 105 & 90 & 100 \\
$\mathrm{PM}_{2.5}$ & 24 hours & 150 & 120 & 40 \\
\hline
\end{tabular}

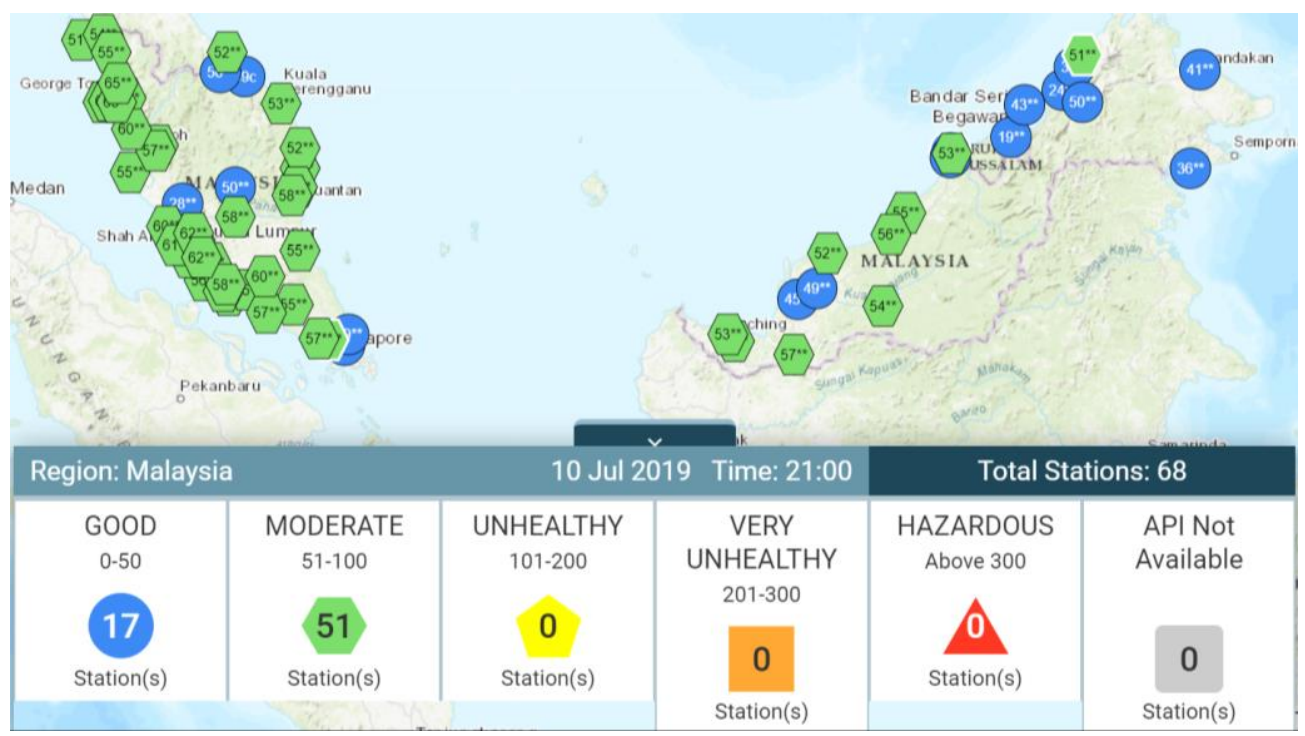

Figure 1. Geographical Location of CAQMS in Malaysia (http://apims.doe.gov.my)

\section{DESIGN OF AIR QUALITY MEASUREMENT SYSTEM}

In [22], hardware and software design of the proposed air quality measurement system using Raspberry Pi has been discussed. In this paper, additional features using webserver hosted in the RaspberryPi for remote monitoring will be presented. The webserver was mainly used to view API and other readings 
from the system for no Internet access scenario. Additional features were included to visualize the information in case of Internet connectivity is available. Air quality officer, user, and system maintainer were the main target of this webserver.

A python-powered web server was implemented using Flask micro web framework [25]. The web server was hosted on port 80 of the Raspberry-Pi local server with IP address of 192.168.1.102. To be globally accessible, port-forwarding technique was used to connect local IP to the global IP. After port-forwarding, user from across the world can access the web server from the Internet by typing in global IP address of the broadband in any web browsers. Several problems arise as it is inconvenient for user to type the long global IP address which is in numbers and the global IP address changes every time the broadband is turn on. To solve these problems, Duck DNS, a free dynamic DNS provider is used. It gives an easy-toremember domain name to the web server and solve the dynamic problem of a global IP address.

The webserver can be used with or without Internet connection. The webserver was originally developed intended for no Internet access scenario such as in deep rural area usage. With Internet connectivity, the webserver extended its visualisation using colourize gauge for API value and Google Maps for location positioning. Other than that, data were send to an online database, Google Firebase for mobile apps development [26]. Figure 2 demonstrates the sample API page with and without Internet connection.

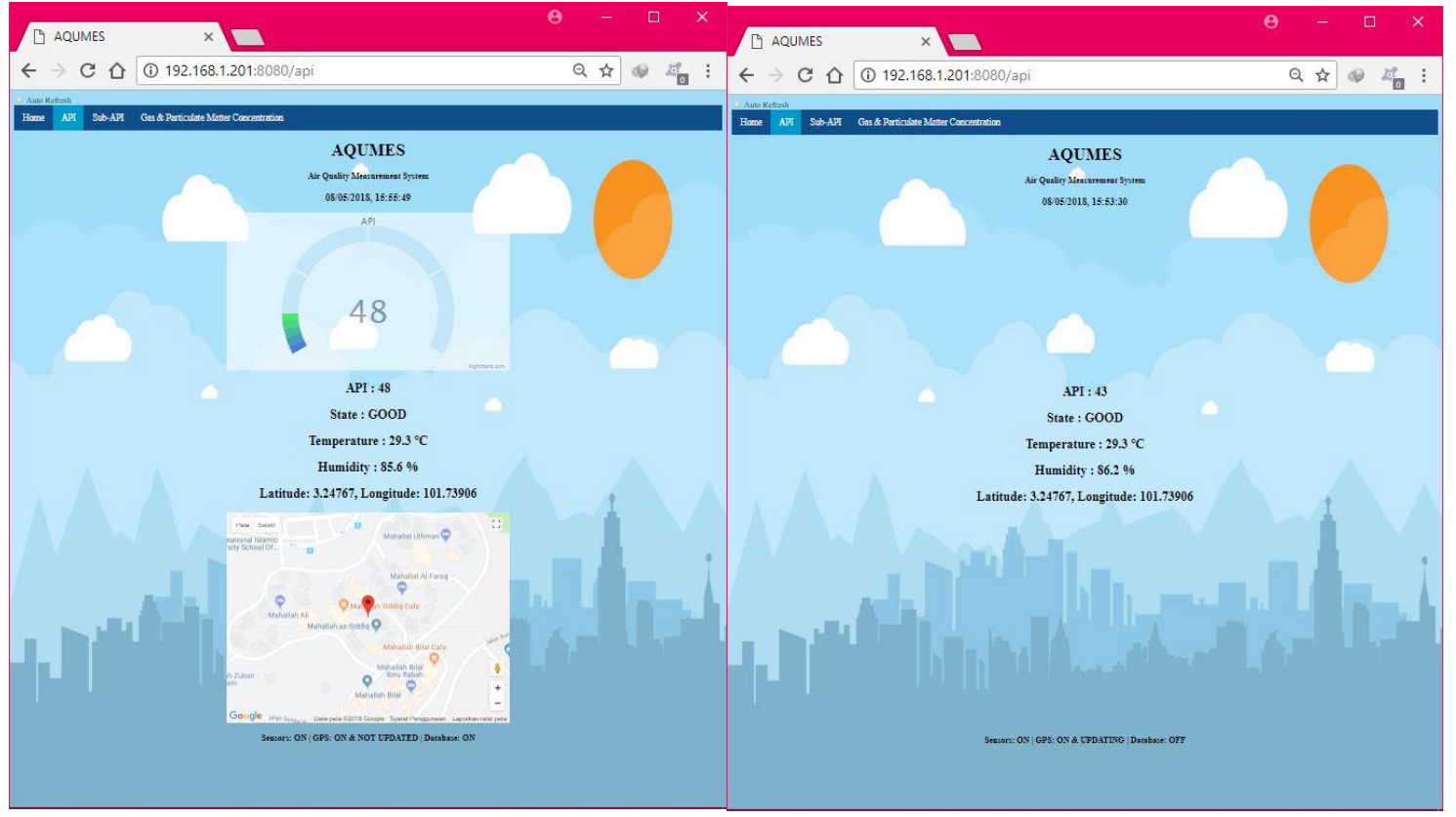

Figure 2. API page with and without internet connection

Several pages were created for the webserver to organize data presentation to users. Home page was made for the user to select desired data such as API, sub-API, or gas and particulate matter concentration page. The API page is displaying API value both in number and visualize it in a colourize gauge to aid user's interpretation on the value. State of the air along with current temperature and humidity level of the air were also included. In term of positioning, current latitude and longitude value which were constantly updated were provide along with Google Map location positioning to ease user identifying the location. As the webserver was developed for remote maintenance as well, status on the system's sensors, GPS, and database were also included to ease maintainer troubleshooting, in case of software problem occurs.

\section{EXPERIMENTAL RESULTS AND DISCUSSION}

In [22], the prototype implementation and validation has been discussed. In this paper, details of each sensor experimentation will be presented, including particulate matters, humidity, temperature, ozone, nitrogen dioxide, sulfur dioxide, and carbon monoxide. Figure 3 shows various sensors used in this research. Lastly, experiment on different road traffic volumes were conducted. 


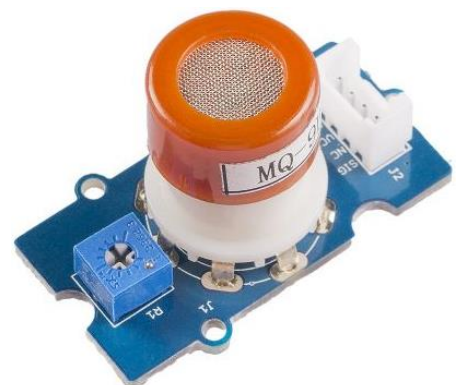

(a)

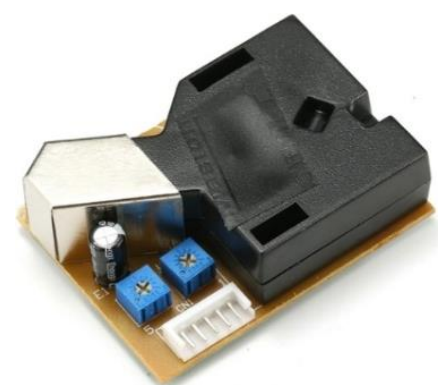

(d)

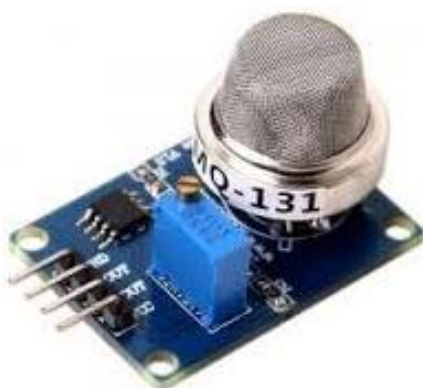

(b)

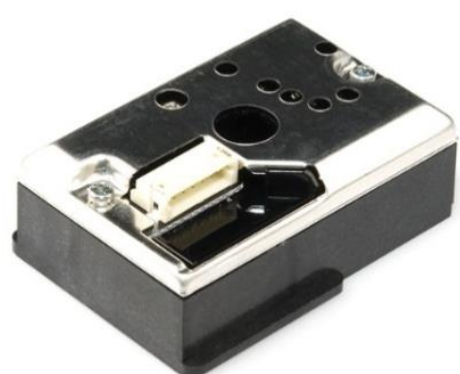

(e)

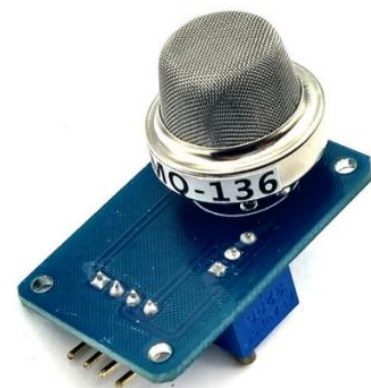

(c)

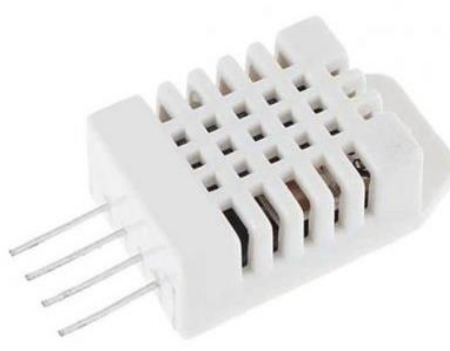

(f)

Figure 3. Various sensors used in the portable air quality measurement system, (a) MQ-9 CO Gas Sensor, (b) MQ-131 O $\mathrm{O}_{3}$ and $\mathrm{NO}_{2}$ Gas Sensor, (c) MQ-136 $\mathrm{SO}_{2}$ Gas Sensor, (d) PPD42NS PM${ }_{2.5}$ Sensor, (e) GP2Y1010AU0F PM 10 Sensor, (f) DHT22 Temperature/Humidity

\subsection{Particulate Matter $\left(\mathbf{P M}_{2.5}\right.$ and $\left.\mathbf{P M}_{10}\right)$ Sensors Experiment}

$\mathrm{PM}_{2.5}$ and $\mathrm{PM}_{10}$ sensors used were PPDN42NS and GP2Y1010AU0F sensors available in the market. Figure 4(a) shows the experimental setup for testing functionality of PPD42NS sensor in detecting dust or particulate matter with size smaller than 2.5-micron level in the air. Baby powder was placed inside a small semi-closed container as a particulate matter sources. An electric fan was used to blow the baby powder from its container to circulate it in the air. The sensor's wires were extended to allow the sensor to be positioned with the baby powder inside a semi-closed container to reduce wind disturbance. The sensor's reading was displayed on a monitor and recorded in the system. Upon exposure to baby powder, the sensor's reading was increased sharply and remained at peak levels for about 30 seconds before declining once the blower was switch-off as shown in Figure 4(b). At the peak, the amount of PM2.5 detected was about 6-8 $\mu \mathrm{g} / \mathrm{m}^{3}$. This pattern of sensor's reading observed following dust exposure indicated that the sensor is up and running properly in the system.

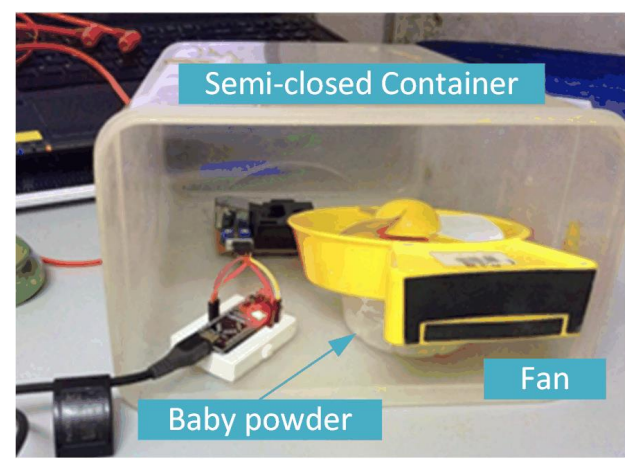

(a)

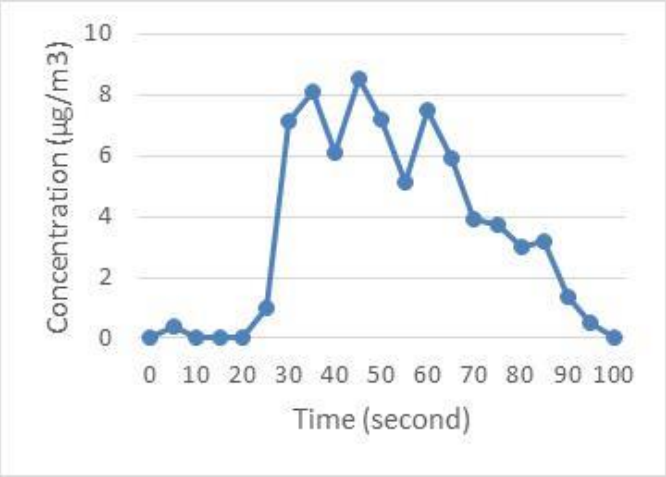

(b)

Figure 4. $\mathrm{PM}_{2.5}$ sensor experimental setup and result, (a) $\mathrm{PM}_{2.5}$ sensor experimental setup, (b) Experimental result of dust in the air $\left(\mathrm{PM}_{2.5}\right)$ 
GP2Y1010AU0F sensor $\left(\mathrm{PM}_{10}\right)$ was validated, as shown in Figure 5(a), using the same methodology for PPD42NS sensor $\left(\mathrm{PM}_{2.5}\right)$ validation. An electric hair-dryer was used to blow the baby powder from its container to circulate it in the air. The sensor responded well to the presence of dust particles judging by the increase in sensor's reading. Not like the PPD42NS sensor which gave relatively low sensor's reading, this sensor demonstrated high sensor's reading as shown in Figure 5(b). At the peak, the sensor's reading reached up to more than $400 \mu \mathrm{g} / \mathrm{m}_{3} \mathrm{PM}_{10}$ particles which suggested that the sensor is able to detect dust particles of 10-microns or less.

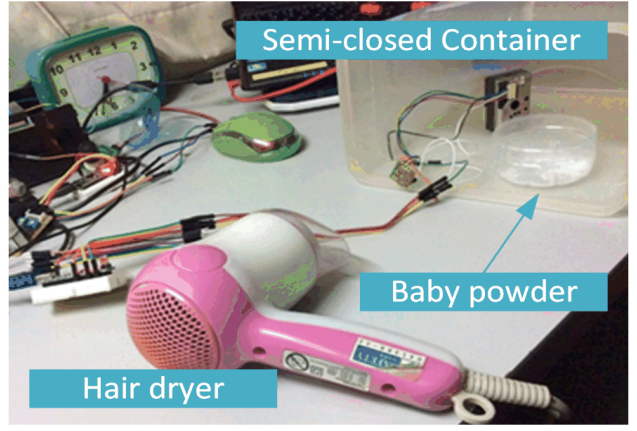

(a)

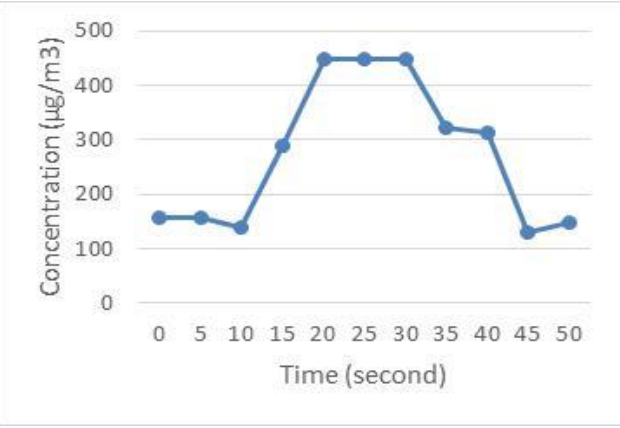

(b)

Figure 5. $\mathrm{PM}_{10}$ sensor experimental setup and result, (a) $\mathrm{PM}_{10}$ sensor experimental setup,

(b) Experimental result of dust in the air $\left(\mathrm{PM}_{10}\right)$

\subsection{Humidity and Temperature Sensor Experiment}

The humidity and temperature sensor used was DHT22. To validate DHT22 function as a humidity sensor, a simple test was done by exposing the sensor to high levels of humidity. Figure 6(a) shows the experimental setup for testing functionality of DHT22 sensor in detecting humidity level in the air. Artificial humidity was generated by using a wet sponge placed inside a semi-closed container. The sensor's wires were extended and positioned near the sponge. The sensor's reading was displayed on a monitor and recorded in the system. Result of this test shows that the sensor was responsive to the levels of humidity generated in the container. The sensor's reading was increased from about $20 \%$ originally to about $60 \%$ after it was placed in the container near the wet sponge as shown in Figure 6(b).

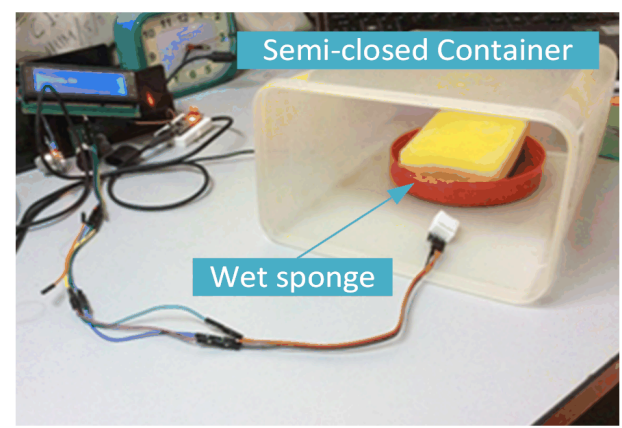

(a)

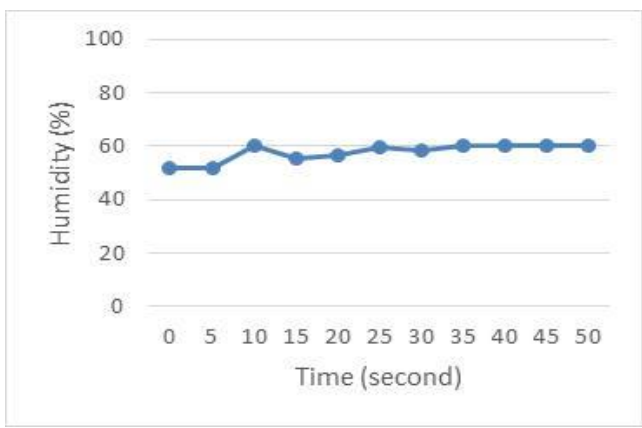

(b)

Figure 6. Humidity sensor experimental setup and result, (a) Humidity sensor experimental setup,

(b) Experimental result of humidity level in the air

To validate DHT22 function as a temperature sensor, another simple test was performed. In this test, a filament bulb was placed in a container to generate heat which would generate warm air in the container as shown in Figure 7(a). The sensor was then positioned near the bulb inside the container for it to detect an increase in air temperature. Figure 7(b) shows the result of the test where sensor's reading was increased from about $32^{\circ} \mathrm{C}$ at the beginning to more than $38^{\circ} \mathrm{C}$ after 50 seconds of exposure. This increase in sensor reading proved that the sensor is working and fully functional. 


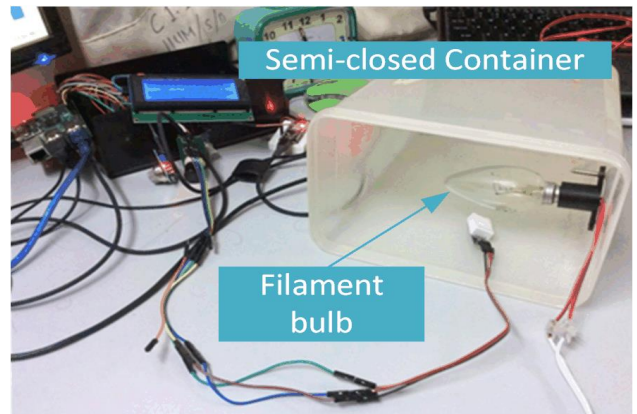

(a)

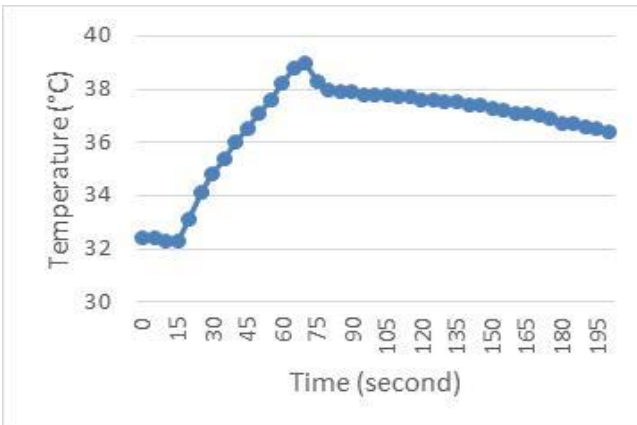

(b)

Figure 7. Temperature sensor experimental setup and result, (a) Temperature sensor experimental setup,

(b) experimental result of temperature level in the air

\subsection{Ozone Sensor Experiment}

Figure 8(a) shows the experimental setup for testing functionality of MQ-131 sensor in detecting $\mathrm{O}_{3}$ gas level in the air. The whole air quality measurement device is placed in a laminar flow cabinet including the MQ-131 sensor. The sensor's reading was displayed on a monitor and recorded in the system. To produce $\mathrm{O}_{3}$ gas, a laminar flow cabinet was used. The cabinet has ultraviolet (UV) lights which is used to purify the inner cabinet from bacteria in its air. The UV lights was turned on while the device was inside the cabinet. The UV ray breaks Oxygen $\left(\mathrm{O}_{2}\right)$ gas in the air and small amount of $\mathrm{O}_{3}$ are formed. Figure 8(b) shows $\mathrm{O}_{3}$ level throughout the validation test. From 0 second, the UV lights was turned on until end of the test. The graph shows a steady increase in $\mathrm{O}_{3}$ level until the end of the test. Thus, the sensor was able to detect the $\mathrm{O}_{3}$ level and works properly.

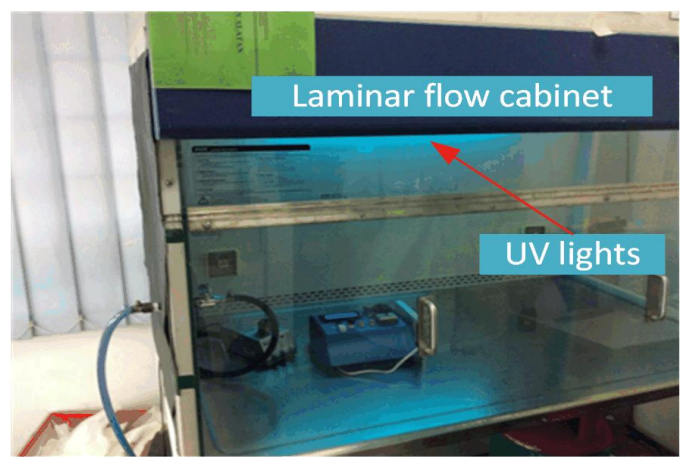

(a)

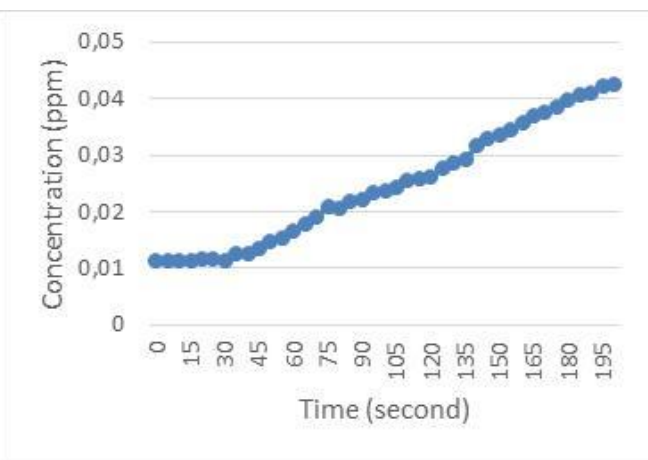

(b)

Figure 8. Ozone sensor experimental setup and result, (a) Ozone sensor experimental setup, (b) Experimental result of ozone level in the air

\subsection{Nitrogen Dioxide Sensor Experiment}

Figure 9(a) shows the experimental setup for testing functionality of MQ-131 sensor in detecting $\mathrm{NO}_{2}$ gas level in the air. To validate its function, the sensor was exposed to $\mathrm{NO}_{2}$ trapped in a small jar. The jar is connected to a conical beaker where a chemical reaction took place to produce $\mathrm{NO}_{2}$ gas. To produce $\mathrm{NO}_{2}$ gas, a small amount of sodium nitrite was mixed with $1 \mathrm{M}$ hydrochloric acid to produce brown $\mathrm{NO}_{2}$ gas, i.e. $\mathrm{NaNO}_{2}+\mathrm{HCl} \rightarrow \mathrm{NaCl}+\mathrm{HNO}_{2} ; 2 \mathrm{HNO}_{2} \rightarrow \mathrm{NO}+\mathrm{NO}_{2}+\mathrm{H}_{2} \mathrm{O} ; 2 \mathrm{NO}+\mathrm{O}_{2} \rightarrow 2 \mathrm{NO}_{2}$. In this reaction, $\mathrm{HNO}_{2}$ was not stable and immediately converted to nitric oxide (NO) which in the presence of oxygen formed brown $\mathrm{NO}_{2}$ gas as shown in Figure 9(a). Figure 9(b) shows $\mathrm{NO}_{2}$ level throughout the validation test. The chemical reaction was made at 0 second. As the $\mathrm{NO}_{2}$ gas reaches the jar containing the sensor through the connecting tube, the reading starts to increase steadily from 55 second onward until the end of the test. Thus, the sensor was able to detect the $\mathrm{NO}_{2}$ level and works properly. 


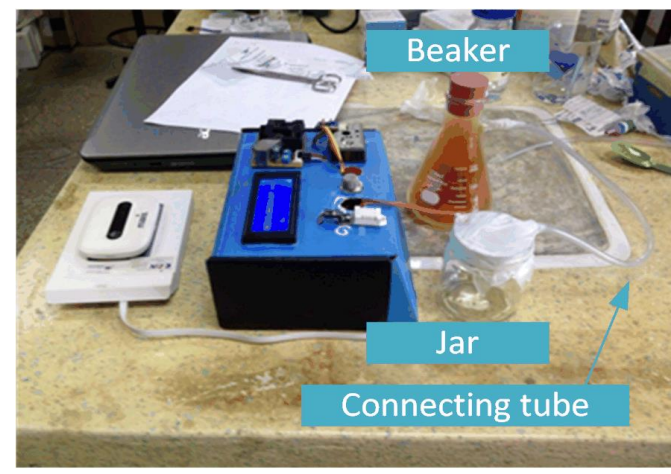

(a)

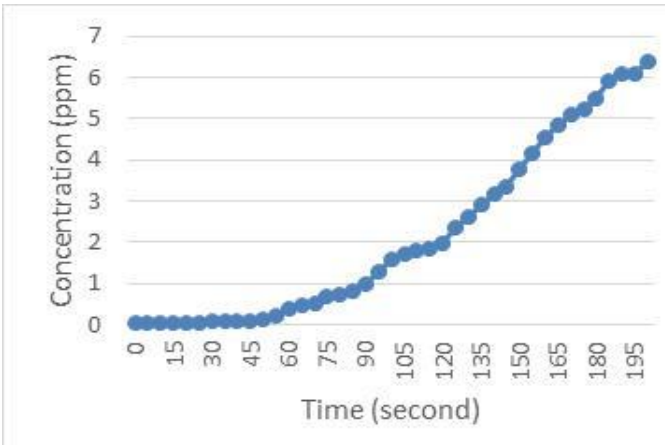

(b)

Figure 9. Nitrogen dioxide sensor experimental setup and result, (a) Nitrogen dioxide sensor experimental setup, (b) Experimental result of $\mathrm{NO}_{2}$ level in the air

\subsection{Sulfur Dioxide Sensor Experiment}

The functionality of MQ-136 sensor in detecting $\mathrm{SO}_{2}$ gas level in the air was validated through a simple test where the sensor was exposed to the gas directly in a small jar as shown in Figure 10(a). Sulphur dioxide was generated by mixing a small amount of sodium bisulfite with a small volume of $1 \mathrm{M}$ hydrochloric acid. This reaction immediately released colourless $\mathrm{SO}_{2}$ in the jar, i.e. $\mathrm{NaHSO}_{3}(\mathrm{~s})+\mathrm{HCl}(\mathrm{aq}) \rightarrow \mathrm{SO}_{2}(\mathrm{~g})+\mathrm{NaCl}(\mathrm{aq})+\mathrm{H}_{2} \mathrm{O}(\mathrm{l})$. In response to $\mathrm{SO}_{2}$, MQ-136 sensor's reading was gradually increased within 20 seconds of exposure from $0 \mathrm{ppm}$ to $70 \mathrm{ppm}$. Since the chemical reaction continually released $\mathrm{SO}_{2}$ gas, the sensor's reading remained high until the end of the test as shown in Figure 10(b). This profile of sensor's reading proved that MQ-136 sensor is working as expected.

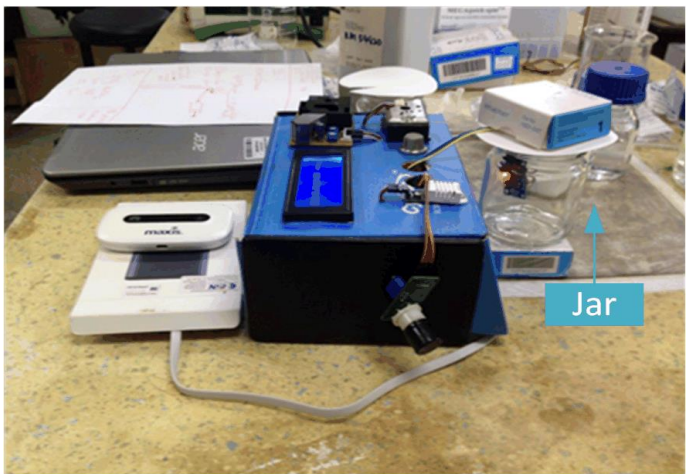

(a)

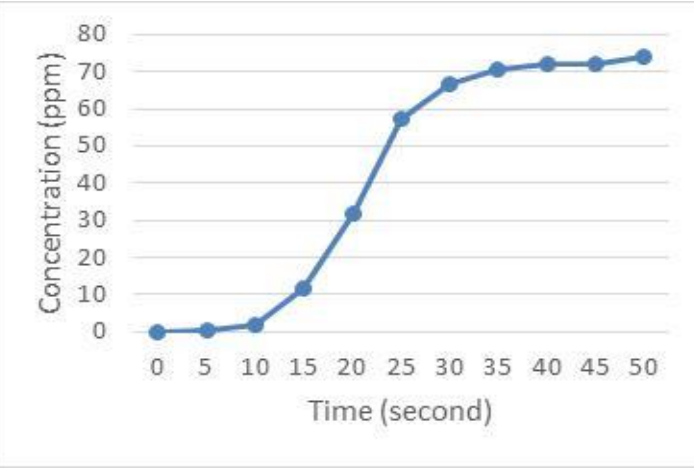

(b)

Figure 10. Sulfur dioxide sensor experimental setup and result, (a) Sulfur dioxide sensor experimental setup,

(b) Experimental result of $\mathrm{SO}_{2}$ level in the air

\subsection{Carbon Monoxide Sensor Experiment}

Figure 11(a) shows the experimental setup for testing functionality of MQ-9 sensor in detecting CO gas level in the air. The sensor's wires were extended to allow the sensor to be positioned inside a small jar which is sealed from outside air. The jar is connected to a beaker where chemical reaction takes place to produce $\mathrm{CO}$ gas. The beaker was positioned on a heating device to heat up the chemical reaction inside. The sensor's reading was displayed on a monitor and recorded in the system. To produce CO gas, a small volume of formic acid was mixed with a small volume of sulphuric acid in a bottle releasing odourless and colourless $\mathrm{CO}$ upon heating, i.e. $\mathrm{H}_{2} \mathrm{SO}_{4}(\mathrm{l})+\mathrm{HCOOH}(\mathrm{l}) \rightarrow \mathrm{CO}(\mathrm{g})+\mathrm{H}_{2} \mathrm{SO}_{4} \cdot \mathrm{H}_{2} \mathrm{O}(\mathrm{l})$. The chemical reaction was made at 0 second. The graph shows an ideal low reading from the beginning of the test until 25 second where a drastic increase of CO level occurs until 30 second as the heated gas has reached the jar containing the sensor. The reading then was stabilized at a very high level until the end of the test as shown in Figure 11(b). Thus, the sensor was able to detect the CO level and works properly. 


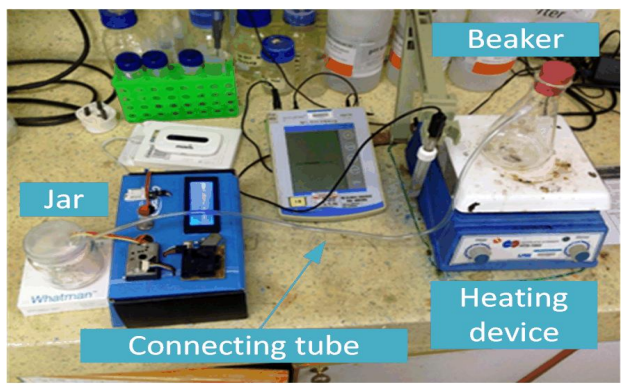

(a)

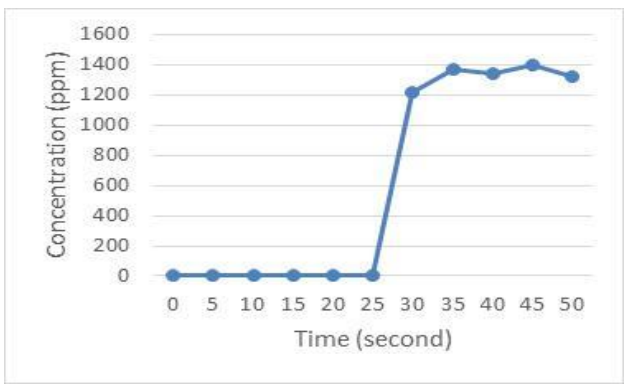

(b)

Figure 11. Carbon monoxide sensor experimental setup and result, (a) Carbon monoxide sensor experimental setup, (b) Experimental result of $\mathrm{CO}$ level in the air

\subsection{Experiment On I}

To evaluate the functionality of the system, a field experiment was conducted to measure pollutant concentrations in areas where traffic volume differs. The system was positioned near a road with low traffic and high traffic. Figure 12(a) and (b) shows the experimental setup for obtaining sub-API readings in low and high traffic area. The experiment was conducted at a roadside near a male hostel area in International Islamic University Malaysia (IIUM). Readings was taken every 30 seconds for 5 minutes. The readings were recorded and saved in the system. Similarly, another experiment was setup for obtaining sub-API readings in an area with heavy-traffic present near a traffic light junction of a busy main road.

Results of these experiments showed that the levels of each pollutant in the two areas differed significantly except for $\mathrm{PM}_{2.5}$ as shown in Figure 12(c) and (d). The levels of $\mathrm{O}_{3}, \mathrm{SO}_{2}, \mathrm{CO}$, and $\mathrm{NO}_{2}$ were all relatively low in the area with low traffic but higher with high traffic. This observation can be explained by the higher amount of gasses accumulated in the area with high traffic. Interestingly, the levels of $\mathrm{PM}_{10}$ were higher in the area with low traffic than that of high traffic. This can be explained by dynamic movement of dust particles in the area as a result of busy traffic which moves away dust particles from the road side. The system seemed to function as anticipated judging by its sensors' ability to differentiate various levels of pollution in low and high traffic areas.

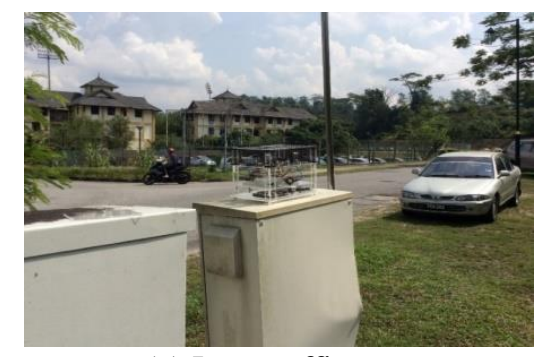

(a) Low traffic area

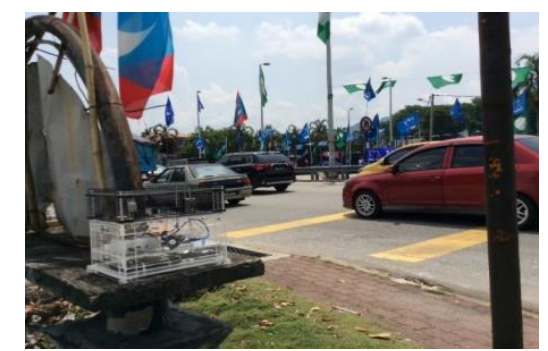

(b) High traffic area

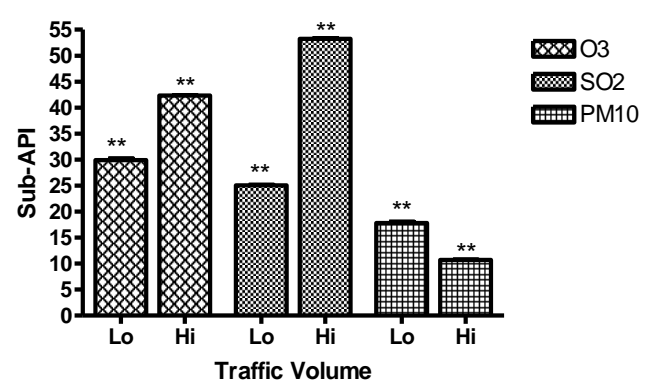

(c) Pollutant levels in low traffic

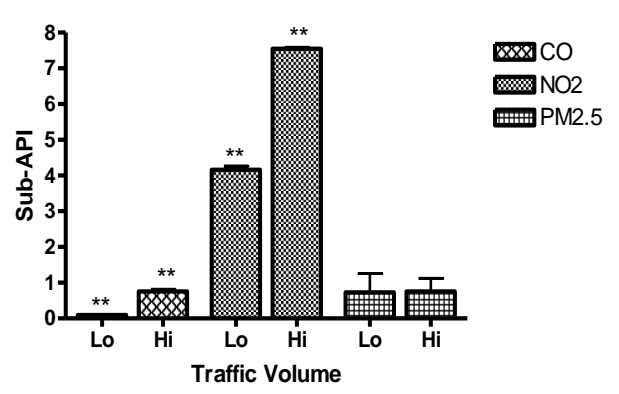

(d) Pollutant levels in high traffic

Figure 12. Measurement of sub-API readings in areas with low and high traffic, (a) Low traffic area, (b) High traffic area, (c) Pollutant levels in low traffic, (d) Pollutant levels in high traffic 


\section{CONCLUSION}

Eight validation tests were done to ensure all six sensors used in the system were able to detect respective physical variables as it should. Based on the outcome of the tests, all sensors are working well. The DHT22 sensor was able to detect temperature and humidity level in the surrounding air and response to their changes efficiently. The MQ-9 sensor was able to detect the presence and concentration of CO gas. The MQ-131 sensor shows its ability to detect and response to change of both $\mathrm{O}_{3}$ and $\mathrm{NO}_{2}$ gases. The MQ136 sensor was able to detect $\mathrm{SO}_{2}$ gas and response to its changes efficiently. The PPD42NS sensor shows a good response to $\mathrm{PM}_{2.5}$ although the reading is a little unstable. The GP2Y1010AU0F sensor shows an excellent response to $\mathrm{PM}_{10}$. As all the sensors were integrated into a system, the system was tested in four experiments. In low traffic area, the system manages to detect ideally low concentration of pollutants. While in heavy traffic area, the system manages to detect a higher concentration of pollutants. This shows that the system works well in detecting all four gases and two particulate matters. Moreover, the proposed system is added with additional feature, i.e. remote monitoring of API and sub-API along with its geotagged location.

\section{ACKNOWLEDGEMENTS}

The authors would like to thank International Islamic University Malaysia (IIUM), Universiti Teknologi MARA (UiTM) Shah Alam and University of New South Wales (UNSW) for providing facilities to support the research work.

\section{REFERENCES}

[1] R. Akhtar and C. Palagiano, "Climate Change and Air Pollution: An Introduction," in Climate Change and Air Pollution: Springer, 2018, pp. 3-8.

[2] B. Brunekreef and S. T. J. T. 1. Holgate, "Air pollution and health," The Lancet. vol. 360, pp. 1233-1242, 2002.

[3] R. A. Rohde and R. A. J. P. o. Muller, "Air pollution in China: mapping of concentrations and sources," PLOS ONE. vol. 10, pp. e0135749, 2015.

[4] J. H. Seinfeld and S. N. Pandis, Atmospheric chemistry and physics: from air pollution to climate change, John Wiley \& Sons, 2016.

[5] Q. Di, Y. Wang, A. Zanobetti, Y. Wang, P. Koutrakis, C. Choirat, F. Dominici, and J. D. J. N. E. J. o. M. Schwartz, "Air pollution and mortality in the Medicare population," The New England Journal of Medicine. vol. 376, pp. 2513-2522, 2017.

[6] A. E. Corrigan, M. M. Becker, L. M. Neas, W. E. Cascio, and A. G. J. E. r. Rappold, "Fine particulate matters: The impact of air quality standards on cardiovascular mortality," Environmental Research. vol. 161, pp. 364-369, 2018.

[7] Z. Zheng, X. Zhang, J. Wang, A. Dandekar, H. Kim, Y. Qiu, X. Xu, Y. Cui, A. Wang, and L. C. J. J. o. h. Chen, "Exposure to fine airborne particulate matters induces hepatic fibrosis in murine models," Journal of Hepatology vol. 63, pp. 1397-1404, 2015.

[8] T.-J. Lee, H. Lim, S.-D. Kim, D.-S. Park, and D.-S. J. J. o. K. S. f. A. E. Kim, "Concentration and properties of particulate matters (PM 10 and PM 2.5) in the Seoul metropolitan," vol. 31, pp. 164-172, 2015.

[9] M. Pascal, G. Falq, V. Wagner, E. Chatignoux, M. Corso, M. Blanchard, S. Host, L. Pascal, and S. J. A. E. Larrieu, "Short-term impacts of particulate matter (PM10, PM10-2.5, PM2. 5) on mortality in nine French cities," Atmospheric Environment. vol. 95, pp. 175-184, 2014.

[10] U. SDGs, "United Nations sustainable development goals," UN. Org, 2015.

[11] W. H. Organization, World health statistics 2016: monitoring health for the SDGs sustainable development goals, World Health Organization, 2016.

[12] T. S. Gunawan, Y. M. S. Munir, M. Kartiwi, and H. Mansor, "Design and Implementation of Portable Outdoor Air Quality Measurement Systemn using Arduino," International Journal of Electrical and Computer Engineering (IJECE), vol. 8, pp. 280-290, 2018.

[13] A. D. Deshmukh and U. B. Shinde, "A low cost environment monitoring system using raspberry Pi and arduino with Zigbee," in Inventive Computation Technologies (ICICT), International Conference on, pp. 1-6, 2016.

[14] N. Castell, F. R. Dauge, P. Schneider, M. Vogt, U. Lerner, B. Fishbain, D. Broday, and A. J. E. i. Bartonova, "Can commercial low-cost sensor platforms contribute to air quality monitoring and exposure estimates?," Environment International. vol. 99, pp. 293-302, 2017.

[15] D. Oletic and V. Bilas, "Design of sensor node for air quality crowdsensing," in Sensors Applications Symposium (SAS), 2015 IEEE, pp. 1-5, 2015.

[16] D. Hasenfratz, O. Saukh, S. Sturzenegger, and L. Thiele, "Participatory air pollution monitoring using smartphones," Mobile Sensing, vol. 1, pp. 1-5, 2012.

[17] J. Dutta, F. Gazi, S. Roy, and C. Chowdhury, "AirSense: Opportunistic crowd-sensing based air quality monitoring system for smart city," in 2016 IEEE SENSORS, pp. 1-3, 2016.

[18] J. Dutta, C. Chowdhury, S. Roy, A. I. Middya, and F. Gazi, "Towards smart city: sensing air quality in city based on opportunistic crowd-sensing," in Proceedings of the 18th international conference on distributed computing and networking, pp. 42, 2017.

\footnotetext{
Performance evaluation of portable air quality measurement system... (Muhammad Farhan Mohd Pu'ad)
} 
[19] M. Ibrahim, A. Elgamri, S. Babiker, and A. Mohamed, "Internet of things based smart environmental monitoring using the Raspberry-Pi computer," in Digital Information Processing and Communications (ICDIPC), 2015 Fifth International Conference on, pp. 159-164, 2015.

[20] S. Kumar and A. Jasuja, "Air quality monitoring system based on IoT using Raspberry Pi," in 2017 International Conference on Computing, Communication and Automation (ICCCA), pp. 1341-1346, 2017.

[21] A. A. Alkandari, S. J. I. J. o. E. E. Moein, and C. Science, "Implementation of Monitoring System for Air Quality using Raspberry PI: Experimental Study," vol. 10, pp. 43-49, 2018.

[22] M. F. M. Pu'ad, T. S. Gunawan, M. Kartiwi, and Z. Janin, "Development of Air Quality Measurement System using Raspberry $P i, "$ in 2018 IEEE 5th International Conference on Smart Instrumentation, Measurement and Application (ICSIMA), pp. 1-4, 2018.

[23] C.-F. Wu, A. Woodward, Y.-R. Li, H. Kan, R. Balasubramanian, M. T. Latif, M. Sahani, T.-J. Cheng, C.-P. Chio, and N. Taneepanichskul, "Regulation of fine particulate matter (PM2. 5) in the Pacific Rim: Perspectives from the APRU Global Health Program," Air Quality, Atmosphere \& Health, vol. 10, pp. 1039-1049, 2017.

[24] R. Afroz, M. N. Hassan, and N. A. Ibrahim, "Review of air pollution and health impacts in Malaysia," Environmental research, vol. 92, pp. 71-77, 2003.

[25] M. Grinberg, Flask web development: developing web applications with python, " O'Reilly Media, Inc.", 2018.

[26] L. Moroney, Moroney, and Anglin, Definitive Guide to Firebase, Springer, 2017.

\section{BIOGRAPHIES OF AUTHORS}

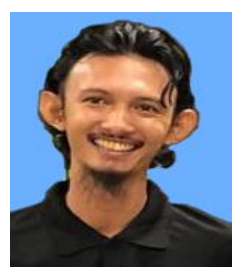

Muhammad Farhan Mohd Pu'ad has completed his B.Eng. (Hons) degree in Electronics: Computer and Information Engineering, International Islamic University Malaysia (IIUM) in 2018 and is currently pursuing his Master in Computer Engineering at the same university. He obtained best final year project award from IEEE Computer Society. His research interests are in instrumentation and signal processing on single board computers.

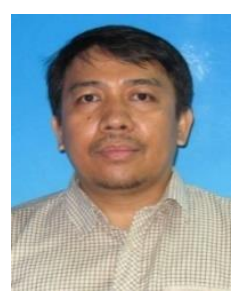

Teddy Surya Gunawan received his B.Eng degree in Electrical Engineering with cum laude award from Institut Teknologi Bandung (ITB), Indonesia in 1998. He obtained his M.Eng degree in 2001 from the School of Computer Engineering at Nanyang Technological University, Singapore, and $\mathrm{PhD}$ degree in 2007 from the School of Electrical Engineering and Telecommunications, The University of New South Wales, Australia. His research interests are in speech and audio processing, biomedical signal processing and instrumentation, image and video processing, and parallel computing. He is currently an IEEE Senior Member (since 2012), was chairman of IEEE Instrumentation and Measurement Society - Malaysia Section (2013 and 2014), Associate Professor (since 2012), Head of Department (2015-2016) at Department of Electrical and Computer Engineering, and Head of Programme Accreditation and Quality Assurance for Faculty of Engineering (2017-2018), International Islamic University Malaysia. $\mathrm{He}$ is Chartered Engineer (IET, UK) and Insinyur Profesional Madya (PII, Indonesia) since 2016, and registered ASEAN engineer since 2018.

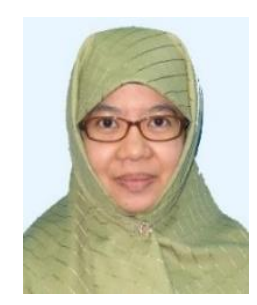

Mira Kartiwi completed her studies at the University of Wollongong, Australia resulting in the following degrees being conferred: Bachelor of Commerce in Business Information Systems, Master in Information Systems in 2001 and her Doctor of Philosophy in 2009. She is currently an Associate Professor in Department of Information Systems, Kulliyyah of Information and Communication Technology, and Deputy Director of e-learning at Centre for Professional Development, International Islamic University Malaysia. Her research interests include electronic commerce, data mining, e-health and mobile applications development.

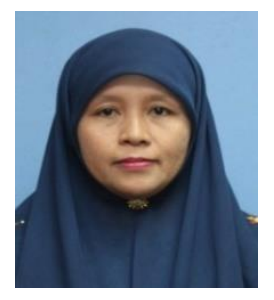

Zuriati Janin received her B.Eng in Electrical Engineering from the Universiti Teknologi Mara, Malaysia in 1996 and MSc. in Remote Sensing \& GIS from the Universiti Putra Malaysia (UPM) in 2001. In 2007, she began her study towards a Ph.D in Instrumentation and Control System at the Universiti Teknologi Mara, Malaysia. She has served as a lecturer at Universiti Teknologi Mara for more than 20 years and currently she is a Senior Lecturer at Faculty of Electrical Engineering, UiTM, Shah Alam. She has been involved with IEEE since 2012 and been mainly working with IEEE Instrumentation \& Measurement Chapter (IM09), Malaysia Section since 2013. The IM09 acknowledged her role as a founder Treasurer in initiating and promoting ICSIMA as a series of annual chapter's flagship conferences since its inception in 2013. She also has more than 10 years experiences in organizing the International Conferences, Workshops and Seminars. Her role as a conference treasurer started since 2005. 